\title{
RESTORATION OF THE WORKING BODY OF THE JOHN DEERE 512 DISK RIPPERWITH MULTI-LAYER FRONT SURFACING
}

\author{
Sergey Strebkov, Alexey Slobodyuk, Andrey Bondarev \\ Belgorod State Agricultural University named after V. Gorin, Russia \\ serwastr@gmail.com,aspl22@yandex.ru, av.bondarev@gmail.com
}

\begin{abstract}
Modern technologies of soil cultivation during cultivation of agricultural crops are aimed at reducing mechanical action due to a justified reduction in the number of technological operations, as well as combining several operations on the technological platform of one machine-tractor unit, performed in one pass. One of the ways to reduce the impact on the soil is to exclude formation turnover during continuous tillage (plowing). For this, deep rippers of various designs are used. The common element for them are the working bodies - metalintensive racks with cutting and crushing surfaces. Due to the difficult working conditions, including a large mass of the unit, high dynamic loads and intense abrasive wear, they determine the failure-free, long-eternity and maintainability of the structure. An analysis of the wear of the tip under operating conditions showed that the limiting state occurs when an average loss of $8.5 \%$ of the weight of the tip by weight wear occurs. The results of micrometeringshowed that the limiting state was linearly changed by the "toe-heel" parameter at an average of $9.7 \%$, and by the "toe-anterior hole" parameter, an average of $16 \%$ of the new value. Therefore, the obvious fact is the presence of $84-90 \%$ of the unused residual resource. In the laboratory of restoration of worn parts of the Belgorod State Agrarian University, the technology of frontal cladding with annealing rollers using heattreated elements was developed to restore the tips of the working bodies of the 512 Disk Ripper. The incomplete use of the resource of the tip of the deep ripper was established when replacing it according to the manufacturer's recommendations. The presence of the residual resource of the part by mass allows to repeatedly restore its operational state. The proposed technology for restoring the tip is $47 \%$ cheaper than purchasing new ones. Moreover, their resource is increased by $50 \%$.
\end{abstract}

Key words: anchor, working body, wear, residual resource, restoration, surfacing, durability.

\section{Introduction}

Modern technologies of soil cultivation during the cultivation of agricultural crops are aimed at reducing mechanical action due to a justified reduction in the number of technological operations, as well as combining several operations on the technological platform of one machine-tractor unit, performed in one pass [1-3].

One of the ways to reduce the impact on the soil is to exclude formation turnover during continuous tillage (plowing). For this, deep rippers of various designs are used. The common element for them are the working bodies - metal-intensive racks with cutting and crushing surfaces. Due to the difficult working conditions, including a large mass of the unit, high dynamic loads and intense abrasive wear, they determine the failure-free, long-eternity and maintainability of the structure [4-6].

If a failure occurs, it is necessary to restore the working state of the part, node, or unit. The existing system is reduced to dealer supply of spare parts and consumables. In this case, the operating costs for maintaining the equipment in working condition increase sharply. The results of experimental restoration of parts of foreign equipment showed that the use of various technologies can reduce the cost of spare parts. In addition, their repeated use makes it possible to solve economic andenvironmental problems of mechanical engineering in many ways [7].

There are several methods for volumetric wear compensation. Filling with liquid metal does not provide high-quality adhesion to the base, does not guarantee the necessary carbon content in the alloy, and requires special metallurgical equipment. Surfacing with an electric arc and flame leads to the appearance of shrinkage thermal cracks during cooling and a decrease in adhesion to the base.

\section{Materials and methods}

The 512 Disk Ripper (Fig. 1) is characterized by a two-element design of the working body, which includes a stand providing load-bearing capacity, and a removable tip designed for loosening the soil to a depth of $60 \mathrm{~cm}$. The tip directly contacts the soil abrasive at high contact pressure and, in this regard, is a "weak" structural element with a resource significantly less than the life of the rack, the failure of which occurs due to fatigue or catastrophic failure. 
The Ripper 512 design provides increased reliability by providing a high level of maintainability. This is manifested in the replacement of a quick-wear element-the anchor (tip), and not the entire rack. It is supplied by the dealer as spare part with high added value. However, their resource is not increased, and manufacturers do not provide measures to improve wear resistance. The resource is provided by the structural material-high-strength cast iron, from which the tip is made by casting. A number of studies have been conducted to assess the possibility of carrying out renovation activities.

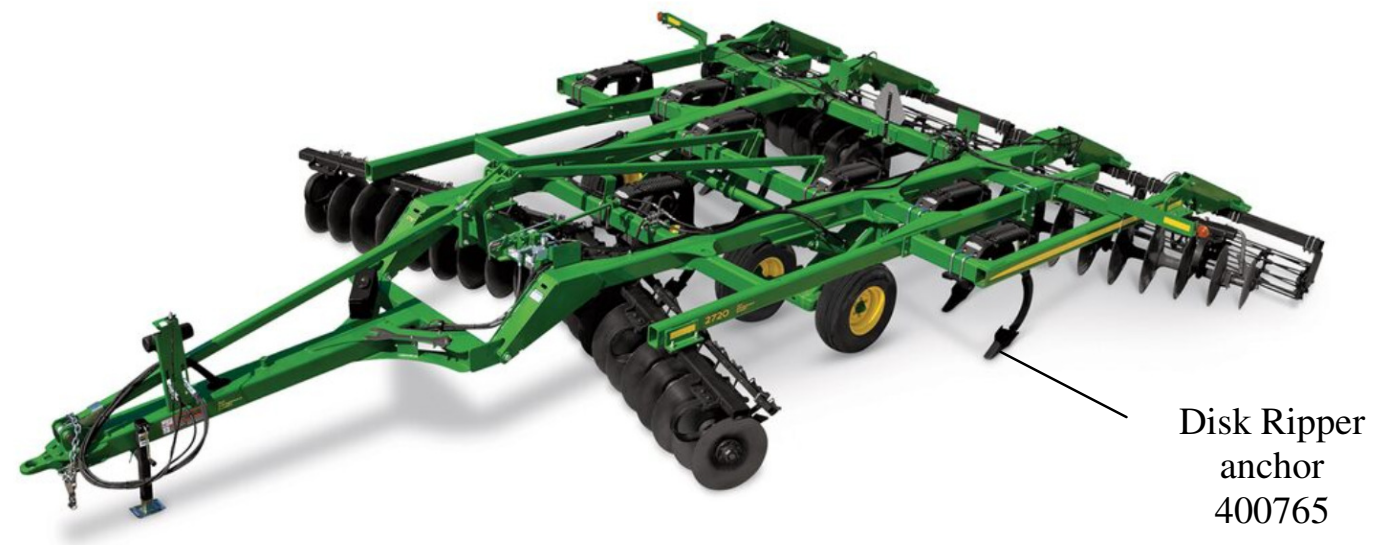

Fig.1. John Deere 512 Disk Ripper with anchor arrangement

In the laboratory of restoration of worn partsof the Belgorod State Agrarian University, the technology of frontal cladding with annealing rollers using heat-treated elements was developed to restore the tips of the working bodies of the 512 Disk Ripper.

It is proposed to perform electric arc welding by successively applying layers of molten metal on top of each other with the inclusion of heat-strengthened elements with high carbon content. This reduces thermal cracking due to annealing at high carbon content.

With this technology, the part is restored to its nominal parameters. Surfacing was carried out in a protective (carbon dioxide) gas environment with a semi-automatic welding machine using a selffluxing wire of НП-30Х10Г 10Tdiameter $1.2 \mathrm{~mm}$. As a heat-strengthened element, a strip of spring steel after heat treatment with a hardness of HRC 50.55 units is taken. During the surfacing process, a special method of "annealing rollers" eliminates the possibility of "bleaching" cast iron and the formation of shrink cracks. At the end of formation of the missing part of the anchor, the surface in contact with the abrasive was deposited with a wear- resistant material using T590 electrodes.

Operational parameters of the technological process were determined experimentally. Current strength was measured by the scale of the apparatus for surfacing. Weight parameters were determined using weights (accuracy $5 \mathrm{~g}$ ). Linear parameters were determined using a caliper (accuracy $0.1 \mathrm{~mm}$, class 1). Temperature was measured using a C-550.1 pyrometer with a range of 400-1600.

The durability test of the samples was carried out on a SMT-1 friction machine by a relative comparison of the two samples. The rollers were made of anchor material and with a deposited layer. Rotational speed is $500 \mathrm{~min}^{-1}$, the load is $1000 \mathrm{~N}$, and duration is $60 \mathrm{~min}$. Medium is an aqueous suspension of silica sand.

To process the experimental data, we used methods of statistical analysis of reliability indicators and a standard package of Excel application programs.

\section{Results and discussion}

Analysis of the wear of the tip under operating conditions showed (Fig. 2) that the limit state occurs, when an average of 0,9 kgorof $8.5 \%$ of the tip weight is lost due to weight wear. The results of micrometering showed that the linear change in the "toe-heel" parameter reached the limit on average with a decrease in size by $34.2 \mathrm{~mm}$ or $9.7 \%$, and the "toe-front hole" parameter reached the limit on average with wear of $65.8 \mathrm{~mm}$ or $16 \%$ of the values of the new anchor. Therefore, the obvious fact is the presence of $84-90 \%$ of the unused residual resource of the anchor.The average square deviation was no more than $10 \mathrm{~g}$ for weight wear and 1-3 $\mathrm{mm}$ for linear wear. 

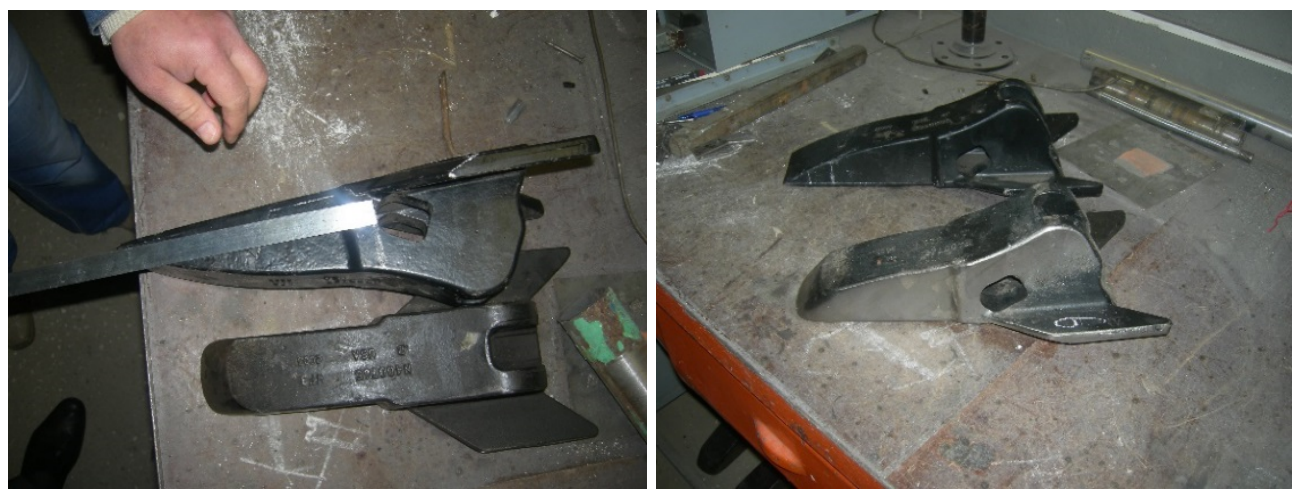

Fig. 2. View of the new and worn-out anchor

The main technological parameter for surfacing is the current strength.Experimental studies have shown that in the range of 90-120 A, recommended by the manufacturer of the surfacing material, a current of $110 \mathrm{~A}$ is optimal.In this case, the part does not overheat and the spray loss (lack of penetration) is minimal (Table 1). The choice was made according to the heating temperature and the output of the surfacing material (mass of wire before surfacing / mass of metal deposited on the part * $100 \%=$ loss of material in \%).

Optimal value of current during surfacing

\begin{tabular}{|c|c|c|}
\hline Amperage, A & $\begin{array}{c}\text { Temperature of the } \\
\text { heating part, }{ }^{\mathbf{C}}\end{array}$ & Loss of material, \% \\
\hline 90 & 852 & 8 \\
\hline 95 & 910 & 6 \\
\hline 100 & 960 & 3 \\
\hline 105 & 1010 & 2 \\
\hline $\mathbf{1 1 0}$ & $\mathbf{1 0 1 2}$ & $\boldsymbol{1}$ \\
\hline 115 & 1108 & 4 \\
\hline 120 & 1218 & 6 \\
\hline
\end{tabular}

Table 1

Studies of changes in the surface resistance against abrasive wear showed (Fig. 3) that surface ligation during frontal surfacing using annealing rollers with a heat-strengthened (high-carbon) element increases the wear resistance compared to the anchor material by 2.4 times, and when applying an additional wear-resistant electrode material T590 - by 5.6 times.

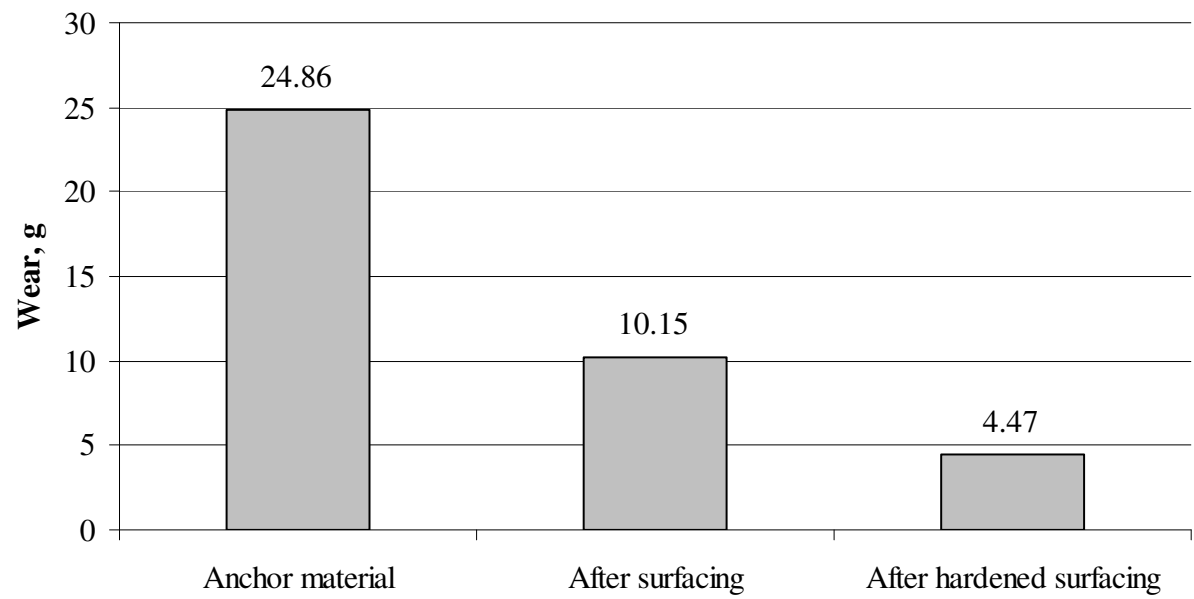

Fig. 3. Potential for increased durability when restoring

The restored anchors in all geometric parameters corresponded to the nominal sizes of the new one (Fig. 4). 

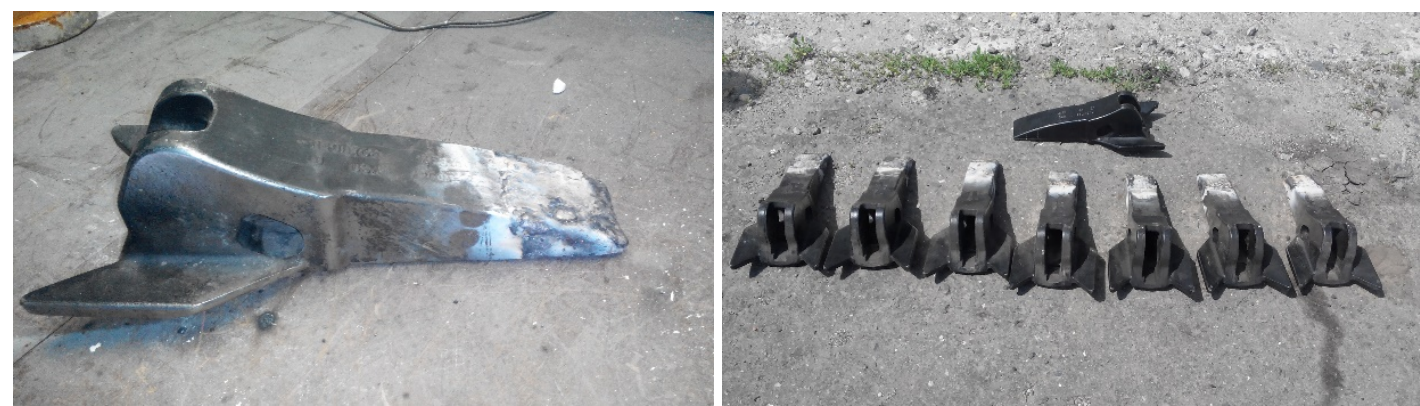

Fig. 4. Anchor after the first restoration and complete set of anchors

After restoration and hardening, the nature of the wear process changes (Fig. 5). The wear rate of the front part is reduced, while ensuring the implementation of the "self-sharpening" effect. This leads to a decrease in the resistivity of the working body.
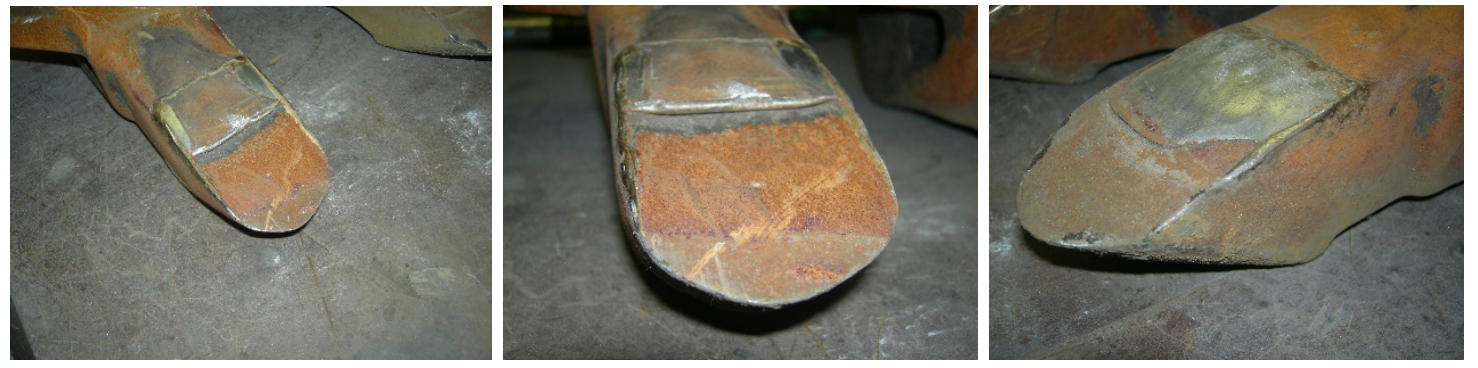

Fig. 5. Change of the anchor wear

During the development of the technological process, the possibility of re-restoration of the anchor surface was checked. The difference between the technological process for the second and third surface restoration is the amount of the applied surfacing material. At the third restoration, it is 3-5\% more (Fig.6). It was found that the cutting surface of the anchor after the third restoration wears out 1.15 times slower than the anchor after the second restoration (Fig. 7). This is due to metallurgical processes during repeated surfacing.
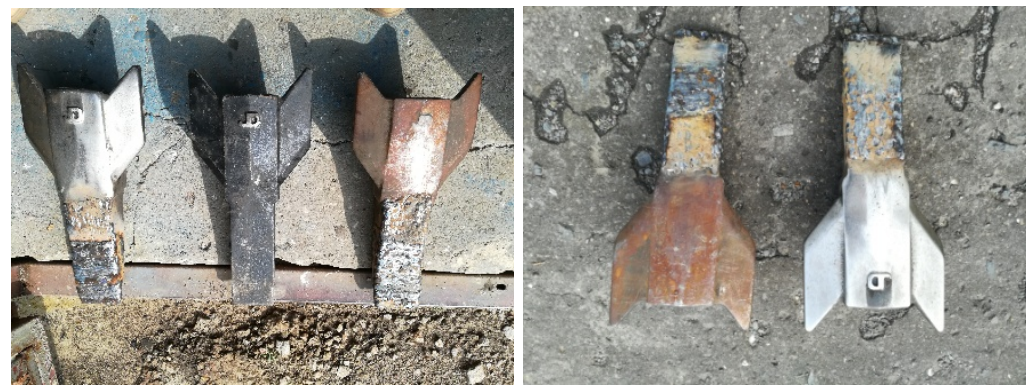

Fig. 6. View of the anchor after the second and third restoration
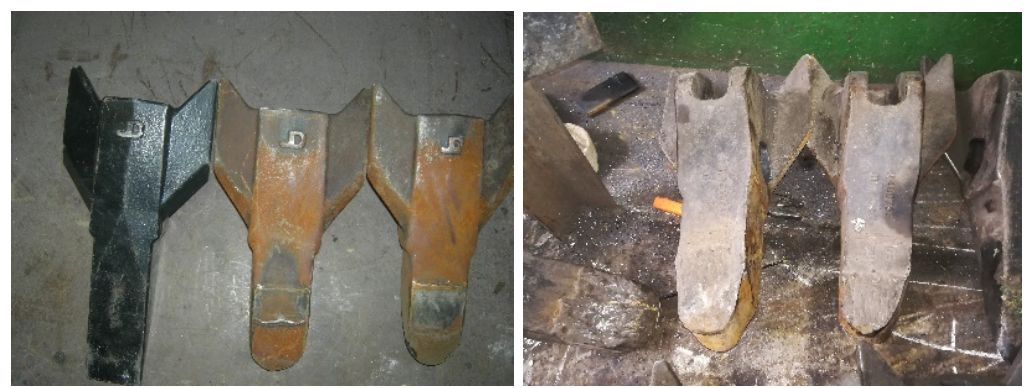

Fig. 7. View of worn anchors after the second and third restoration

However, the feasibility of recovery is lost when weight wear is $28-32 \%$ of the weight of the new anchor. This is due to the wear not of the front surface of cutting and crumbling, but to the loss of 
mass of the side surfaces of the anchor and its "wings". The remains of a previously restored and strengthened surface are seen in Fig. 8. In this case, the loosening process is completely disrupted.

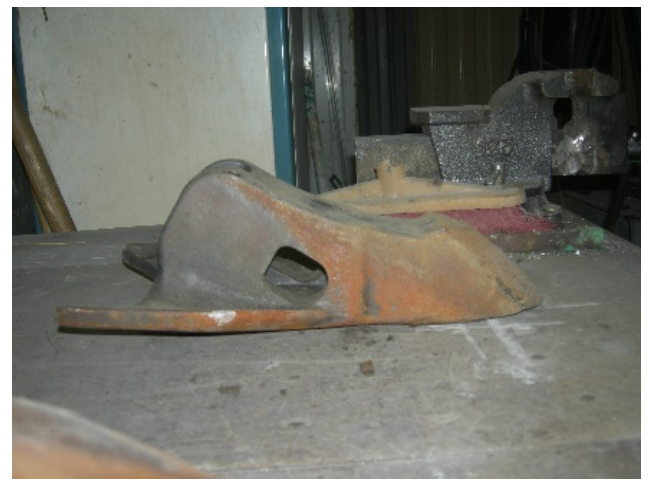

Fig. 8. View of the extremely worn-out anchor that cannot be restored

Operation in real conditions of the Sukmanovka SPK in the Belgorod region showed an increase in the resource from 600 ha to 900 ha at a processing depth of $25.30 \mathrm{~cm}$ on loam and sandy loam soils.

\section{Conclusions}

So, the incomplete use of the resource of the tip of the deep ripper was established, when replacing it according to the manufacturer's recommendations. The presence of the residual resource of the part by mass allows to repeatedly restore its operational state.The proposed technology for restoring the tip by front surfacing with annealing rollers with the use of heat-treated elements and subsequent application of a wear-resistant coating T590 restores it to its nominal size and completely resumes its working state. When using the surfacing wire NP-30H10G10T with a diameter of $1.2 \mathrm{~mm}$, the surfacing should be carried out at a current of $110 \mathrm{~A}$. Potentially, the resource can be increased by 2.44-5.50 times. In real operating conditions, it increased by 1.5 times. The use of this recovery method makes anchors at the first restoration $47 \%$ cheaper than new ones. Renovation of handpieces increases their resource by $50-54 \%$. The third and subsequent renewal of the resource provides a superprofit due to the full depreciation of anchors.

\section{References}

[1] Skuriatin N. F. Resource saving when sowing grain crops. [Text] / N. F. Suratin, A. P. Zacharzewski, A. S. Novitsky, L.A. Zhilyakov, A.V. Bondarev. - Moscow: Belgorod: Central collector of libraries "BIBKOM", 2015, 334 p. (In Russian)

[2] Skuriatin N. F. Methods of increasing the efficiency of using tractor transport and technological aggregates [Text] / N. F. Skuriatin, A.V. Bondarev, B. S. Zdanovich, E. V. Solovyov, S. V. Solovyov. - Moscow; Belgorod: Central library collector BIBKOM LLC, 2017, 161 p. (In Russian)

[3] New technical solutions for combined sowing of grain crops: monograph. / N. F. Skuriatin, A.V. Bondarev, A. S. Novitsky, A. L. Zhilyakov, A. S. Kulikov. - Moscow; Belgorod: Central library collector BIBKOM LLC, 2018, 144 p. (In Russian)

[4] Kazakov, K. V. Foreign agricultural machinery: Monograph [Text] / K. V. Kazakov, A. N. Makarenko, I. V. Martynova, A.V. Machkarin, K. N. Putienko, A.V. Ryzhkov, Yu. V.Saenko, O. A. Chekhov - Moscow; Belgorod: Central collector of libraries "BIBKOM", 2016, 200 p. (In Russian)

[5] Vodolazskaya N. V. Reliability and operation of technical systems: monograph/ N. V. Vodolazskaya, S. V. Strebkov. - Belgorod: Zebra Publishing house, 2017, 152 p. (In Russian)

[6] Slobodyuk A. P. About the reasons for the destruction of spring racks of disk drives. / Slobodyuk A. P. // Innovation in agriculture: Problems and prospects: collection of scientific works. FGBOU VPO BSAA after V. Gorin No.2. - Belgorod: BSAA, 2014, pp. 27-41. (In Russian)

[7] Strebkov, Sergey/ Economic assessment of the recovery of aluminum radiator by gas-dynamic spraying / Sergey Strebkov, Andrey Bondarev, Alexey Slobodyuk //18th International Scientific Conference Engineering for Rural Development Proceedings, May 22-24 2019. Volume 18. - pp. 1772-1779. DOI:10.22616/ERDev2019.18.N178 